\title{
Bilateral Pedicled Superficial Epigastric Flap in the Management of Circumferential Combined Degloving and Full Thickness Burn Hand Injury-A Case Report
}

\author{
Medhat E. Habib, Christoph H. Reuter
}

Department of Plastic, Reconstructive and Craniofacial Surgery, Mafraq Hospital, Abu Dhabi, UAE.

Email: medhatemil1@hotmail.com

Received February $10^{\text {th }}, 2012$; revised March $9^{\text {th }}, 2012$; accepted April $3^{\text {rd }}, 2012$

\begin{abstract}
We report a case of combined hand trauma in the form of circumferential degloving injury of the hand with full thickness friction burns of the hand, forearm and the distal part of the upper arm. On exploration the hand was found avascular with loss of vital structures and full thickness burns. As a salvage procedure the hand was embedded in the subcutaneous tissue of the abdomen for 4 weeks and after that elevated as an inferiorly based flap on the bilateral superficial inferior epigastric arteries. Two weeks later the hand was freed by division of the base of the flap bilaterally. The details and description of the injury, the procedure and the outcome are discussed.
\end{abstract}

Keywords: Hand Burn; Mutilating Degloving Injury; Superficial Inferior Epigastric Artery Flap

\section{Introduction}

Deep Burns and degloving injuries are known devastating types of trauma to the hand. Combination of both with avascularity of the hand represent a surgical challenge. Many cases necessitate amputation of the hand. The patient's opinion, social and working requirements should be taken into consideration in the management of these cases. We report a case with a bad combination of both types of injury and its management.

\section{Case Report}

A 25 years old unmarried gentleman sustained a complex mutilating circumferential degloving crush injury and third degree burn injury to his right upper limb when his hand was trapped in a steam rolling machine for making carpets under high temperature.

The patient suffered a combination of full thickness burns of his right hand, whole forearm and the distal part of the right upper arm with a mutilating injury to the hand (Figure 1). The burn was of a full thickness degree extending from the tips of the fingers till $7 \mathrm{~cm}$ above the elbow proximally in the upper arm. It reached deep to the subcutaneous fat and coagulated the cutaneous nerves and the blood vessels. The hand injury was in the form of circumferential distally based avulsion flap from the wrist level to the proximal interphalangeal joints of all the fingers and the interphalangeal joint of the thumb. The skin over the palm and the dorsum of the hand was partially lost and wrinkled distally in a degloving way with loss of tissue of the wrist and distal forearm (Figure 2). The soft tissues of the hand were crushed and burned. At the palmar surface, the flexor tendons were partially cut with loss of lumbrical, thenar and hypothenar muscles. The vessels were avulsed and coagulated distal to the deep palmar arch including the metacarpal and common digital arteries. The branches of the median nerve were exposed (Figure 3). At the back of the hand the extensor tendons were exposed but the paratenon was found intact. There was amputation of the terminal phalanges of the right little and ring fingers with partial amputation of the terminal phalanx of the middle finger. There was no vascularity of all the fingers. The patient had

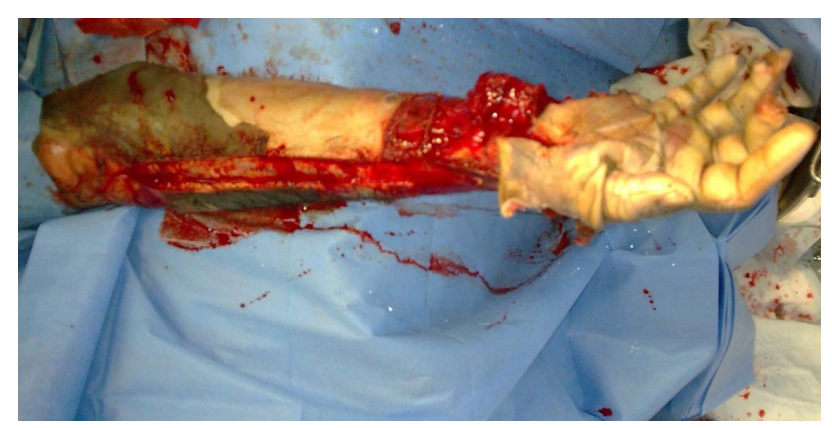

Figure 1. Full thickness circumferential burns of the right hand, forearm and distal part of the arm with distally based degloving injury of the hand. Escharotomy incisions done on the forearm. 


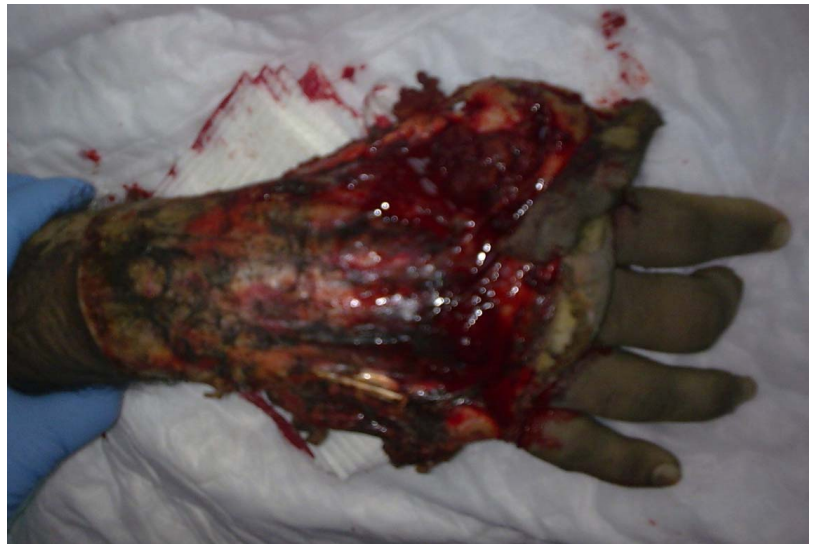

Figure 2. Extent of injury at the dorsum of the wrist and hand with burns of the subcutaneous tissues and tendons.

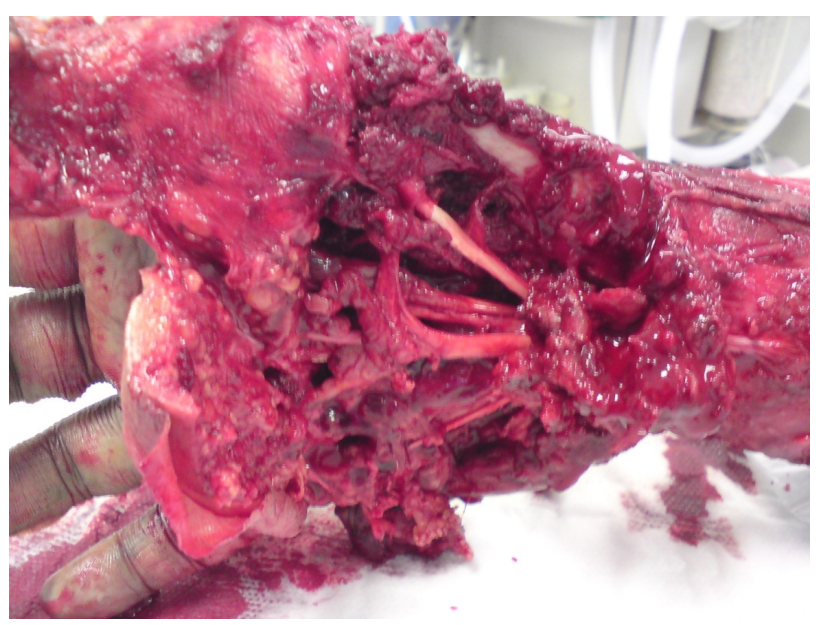

Figure 3. Avulsion of the vessels with loss of some of the short muscles of the hand.

also fracture and bony loss of the olecranon process of the ulna.

In the Emergency Department, immediate resuscitation was done with escharotomy and fasciotomy of the right forearm and arm. Following that the blood flow could be detected by Doppler machine at the radial and ulnar arteries up to the level of the deep palmar arch just distal to the carpal bones.

The injury and possible surgical options were discussed with the patient. The patient and his family requested not to amputate the hand. Due to extensive coagulation of the deep and superficial veins up to the middle of the humerus the patient was not a candidate for a microvascular flap coverage.

It was decided to create a flap in the abdomen to keep the hand in it. The dead burned avascular skin on the hand and fingers was removed and the hand with bones and tendons were buried in a flap created in the abdominal wall based on bilateral superficial inferior epigastric arteries through an oblique incision in the right iliac fossa. Dissection was done under the skin and subcutaneous tissue of the lower abdomen extending from the right iliac fossa through the infraumblical region to the left iliac fossa and the hand was kept in that pocket. The full thickness burns of the right forearm and upper arm were tangentially excised down to the subcutaneous tissue and skin graft was applied to cover these areas (Figure 4). The areas were dressed with silver dressing (Acticoat) every third day.

One month later, elevation of the bilateral superficial epigastric artery flap was performed with folding the flap in a cephalic to caudal direction on the palmar aspect of the hand (Figure 5). The hand was kept at 90 degrees to the level of the abdomen. Skin graft was applied on the donor site of the abdomen. The distal part of the flap had superficial necrosis and was skin grafted. Six weeks post trauma, complete division of the flap was done and the hand was completely freed from its abdominal attachment. The patient underwent a series of debridement and skin grafting operations till the wounds healed well. Three and half months later, creation of a web space between the right index and middle fingers was done (Figure 6). The patient was kept on physiotherapy to improve his range of movement of the joints. The patient had flicker of movement at the wrist joint, limited movement at the elbow joint to 150 degrees. He was supposed to undergo further procedures to separate the other fingers but he was satisfied with the result and had to go back to his home country. The follow up period was nearly one year.

\section{Discussion}

Many procedures were described for coverage of raw areas of the hand. We embedded the hand in the subcutaneous tissue of the abdomen and later on raised it based

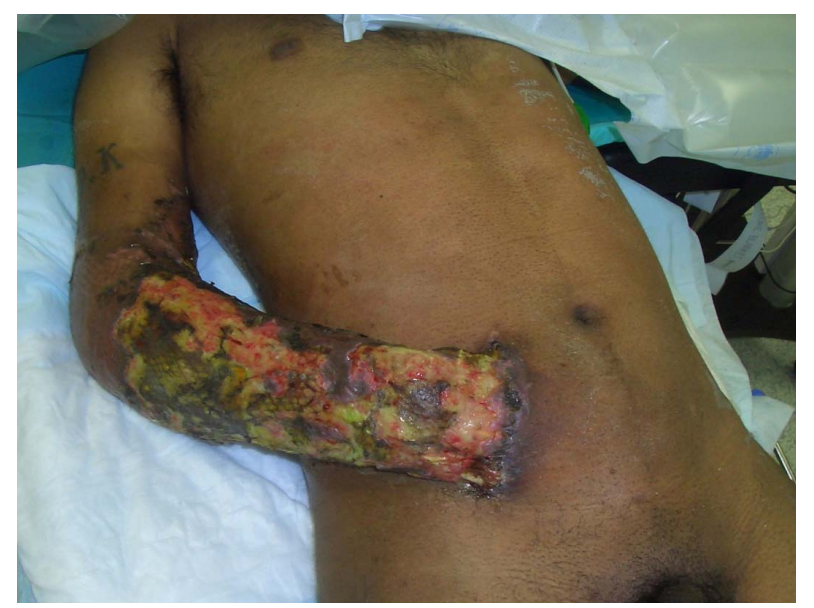

Figure 4. Hand embedded in the abdomen. Forearm skin grafted with some areas of graft loss. 


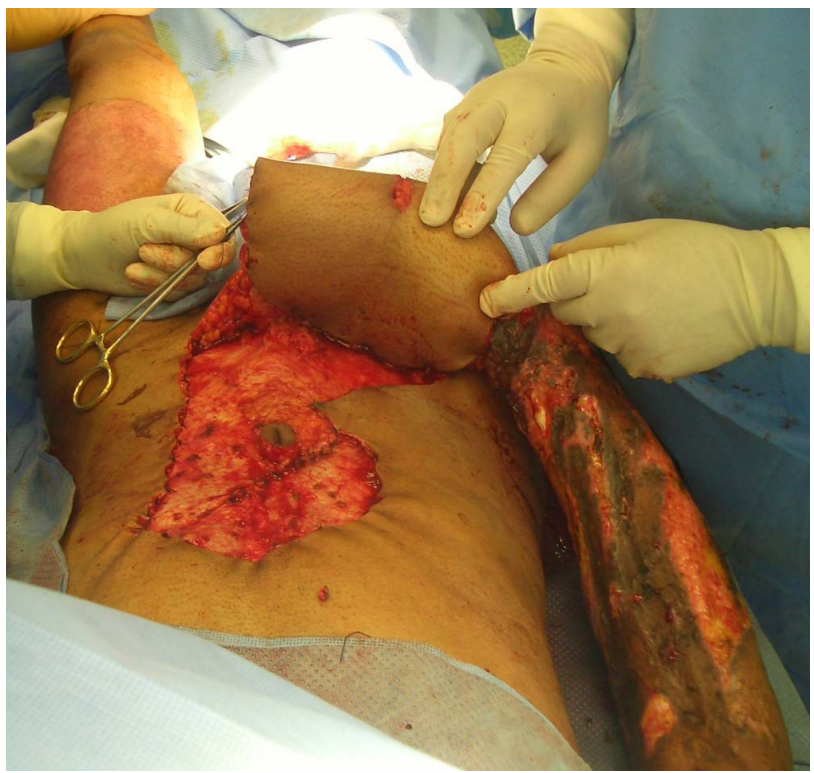

Figure 5. The hand is partially elevated from the abdomen and covered with bilateral superficial epigastric artery flap.

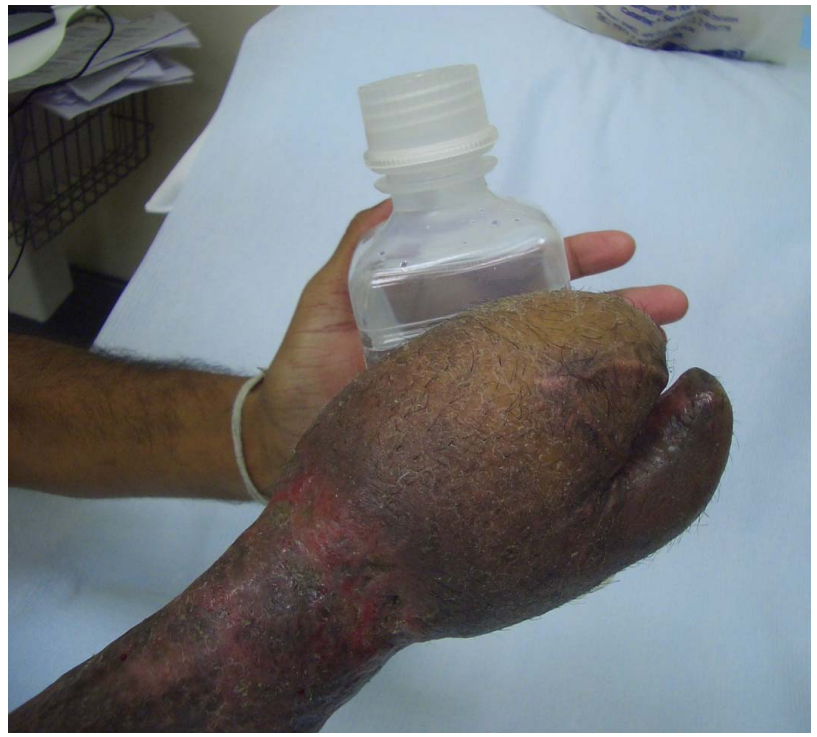

Figure 6. The patient is using his right hand to support in holding items. Note the first stage of fingers separation.

on the bilateral superficial inferior epigastric artery (SIEA) flap. The SIEA flap was used by many reconstructive surgeons to cover defects of the hand but in different ways. Stevenson et al. used a lenticular fashion flap supported by the superficial inferior epigastric artery and veins to cover smaller wounds of the distal upper extremity. They closed the donor site in a linear fashion [1]. Sabapathy et al. used inferiorly based abdominal flaps centered on the superficial inferior epigastric artery with non-vascularised corticocancellous bone graft from the iliac crest to cover dorsal defects of the digits with bony loss. When two or more adjacent fingers were involved, the fingers were syndactylised and a larger SIEA flap was used [2]. Dong et al. used perforator free flap from the superficial circumflex iliac artery or the superficial inferior epigastric artery to cover defects of the hand and forearm [3]. Nasr et al. used a thin SIEA free flap for resurfacing areas of tissue loss on the hands. They removed the deep subcutaneous fat totally while superficial subcutaneous tissue was thinned and a fat tissue layer was left under the skin to protect the subdermal network [4].

To cover defects at the dorsal and the volar surfaces of an injured hand, a combination of flaps was used by many authors.

Thatte $e$ al. reported a case in which the dorsum of the hand was covered by a superficial external pudendal artery (SEPA) axial pattern flap and the volar surface by a flap fashioned from the anterior rectus sheath, which in turn was covered with a split-skin graft [5]. Koncilia et al. combined a pedicled Scarpa's fascia flap and a groin flap to cover the dorsal and palmar aspects of the fingers in a severely crushed hand case [6]. Choi et al. used a combination of superficial epigastric artery flap to cover a raw area at the palm and a groin flap to cover a raw area at the dorsum of the hand in a blast injury case [7].

In our case, the area exposed was circumferential involving all the fingers, hand and wrist with full thickness burns of the forearm and upper arm and required a bigger surface area for coverage. We used a flap based on the superficial inferior epigastric artery folded on itself for coverage of both surfaces of the hand. We found that it is a reliable flap in spite of having superficial necrosis of its distal part.

Dorafshar et al. studied the anatomy of the SIEA and found that the mean arterial diameter was $0.96 \mathrm{~mm}$ and the mean venous diameter was $2.27 \mathrm{~mm}$ [8].

Holm et.al studied the vascular territory of the superficial epigastric artery flap on 10 patients undergoing autologous breast reconstruction with the superficial inferior epigastric perforator flap and five patients undergoing aesthetic abdominoplasty with isolation of the abdominal flap on the superficial epigastric vessels. They found that the true angiosome of the superficial epigastric artery is located laterally on the ipsilateral hemiabdomen. Its random extension is unreliable and ranges most frequently only to the midline. They concluded that survival of the skin and subcutaneous fat taken laterally to the border of the contralateral rectus sheath seems questionable [9].

In our case the flap was raised based on the bilateral superficial inferior epigastric arteries so there was no problem with the viability of the skin and subcutaneous fat of the flap on either side of the arterial supply territory. 
The patient was finally satisfied with the result as his hand was maintained. Aesthetically the salvaged hand was presenting itself as bulky with a syndactyly of the 3 remaining long fingers. Never the less the patient preferred the current situation rather than being amputated. He is using his hand as a supportive aid to the other hand in holding objects. He needs further procedures and physiotherapy to improve the shape and function of the hand.

We feel that the bipedicled superficial epigastric flap is a valuable option of surgical management for such type of complex cases especially if the patient is refusing amputation.

\section{REFERENCES}

[1] T. R. Stevenson, T. R. Hester, E. C. Duus and R. O. Dingman, "The Superficial Inferior Epigastric Artery Flap for Coverage of Hand and Forearm Defects," Annals of Plastic Surgery, Vol. 12, No. 4, 1984, pp. 333-339. doi:10.1097/00000637-198404000-00005

[2] S. R. Sabapathy, H. Venkatramani, T. Giesen and A. S. Ullah, "Primary Bone Grafting with Pedicled Flap Cover for Dorsal Combined Injuries of the Digits," Journal of Hand Surgery (European Volume), Vol. 33, No. 1, 2008, pp. 65-67. doi: $10.1177 / 1753193407087868$

[3] H. Dong, H.-W. Wang, H.-G. Wang, W.-Z. Wu and C.-Y. Zhao, "Reconstruction of Soft Tissue Defect of the Extremity with the Perforator Flap from the Inguinal Region,” Chinese Medical Journal, Vol. 122, No. 23, 2009, pp. 2861-2864.
[4] S. Nasr and M. A. Aydn, "Wide Combined Thin Free SCIA/ SIEA Flap," Annals of Plastic Surgery, Vol. 61, No. 6, 2008, pp. 627-631. doi:10.1097/SAP.0b013e31816d82f5

[5] R. L. Thatte, U. A. Patil and L. D. Dhami, "The Combined Use of the Superficial External Pudendal Artery Flap with a Flap of the Anterior Rectus Sheath for the Simultaneous Cover of Dorsal and Volar Defects on the Hand,” British Journal of Plastic Surgery, Vol. 39, No. 3, 1986, pp. 321-326. doi:10.1016/0007-1226(86)90041-X

[6] H. F. Koncilia, A. P. Worseg, R. Kuzbari and J. Holle, "The Combined Use of a Pedicled Scarpa's Fascia Flap and a Groin Flap for Simultaneous Coverage of Dorsal and Palmar Finger Defects,” Journal of Hand Surgery (European Volume), Vol. 22, No. 5, 1997, pp. 620-622. doi:10.1016/S0266-7681(97)80360-9

[7] J. Y. Choi and K. C. Chung, "The Combined Use of a Pedicled Superficial Inferior Epigastric Artery Flap and a Groin Flap for Reconstruction of a Dorsal and Volar Hand Blast Injury,” Hand, Vol. 3, No. 4, pp. 375-380.

[8] A. M. Dorafshar, M. Januszyk and D. H. Song, "Anatomical and Technical Tips for Use of the Superficial Inferior Epigastric Artery (SIEA) Flap in Breast Reconstructive Surgery," Journal of Reconstructive Microsurgery, Vol. 26, No. 6, 2010, pp. 381-389. doi:10.1055/s-0030-1249604

[9] C. Holm, M. Mayr, E. Höfter and M. Ninkovic, “The Versatility of the Siea Flap: A Clinical Assessment of the Vascular Territory of the Superficial Epigastric Inferior Artery," Journal of Plastic, Reconstructive \& Aesthetic Surgery, Vol. 60. No. 8, 2007, pp. 946-951. doi:10.1016/j.bjps.2005.12.066 